NIF Cryogenic Target Systems Program Fiscal Year 2003 First Half Report

T. P. Bernat

August 1, 2003 


\section{NIF Cryogenic Target Systems Program Fiscal Year 2003 First Half Report}

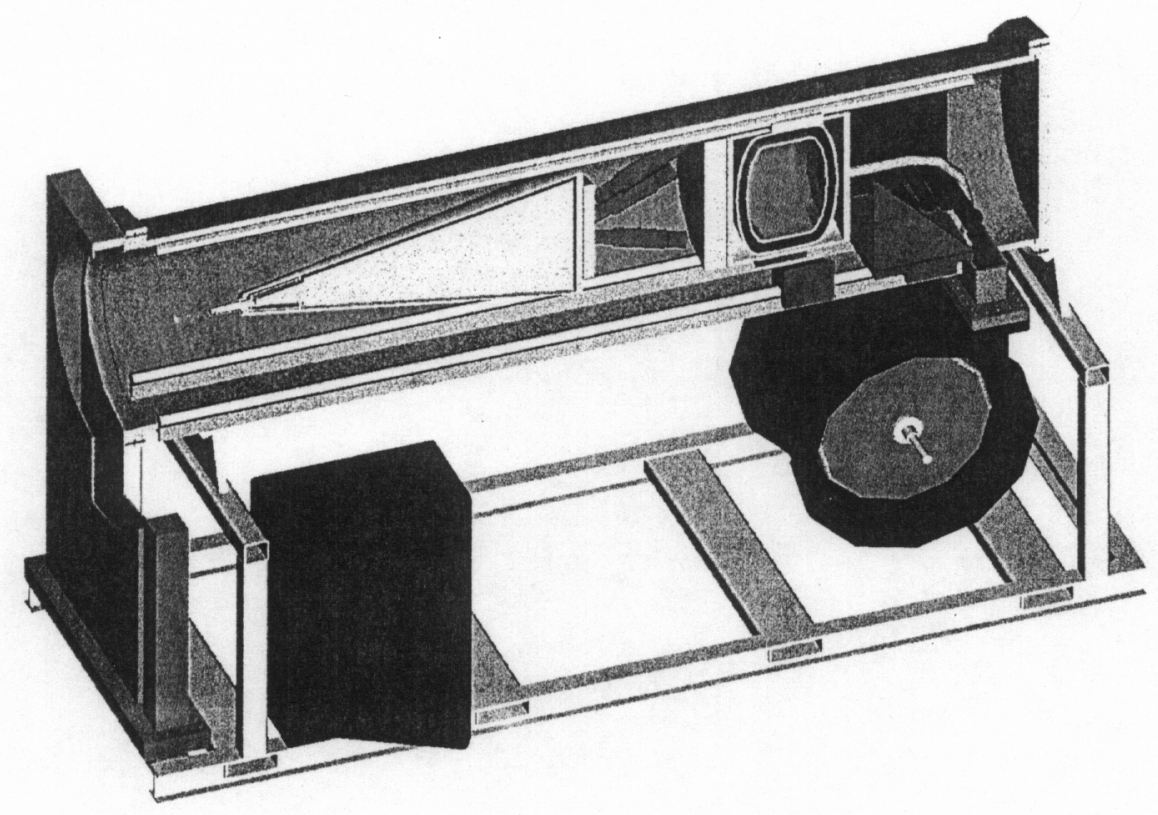

July 2003

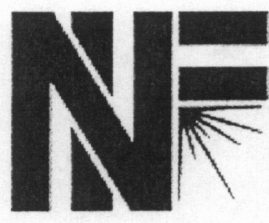

NATIONAL IGNITION FACILITY

Lawrence Livermore National Laboratory 7000 East Avenue Livermore, CA 94550 
DISCLAIMER

This document was prepared as an account of work sponsored by an agency of the United States Government. Neither the United States Government nor the University of California nor any of their employees, makes any warranty, express or implied, or assumes any legal liability or responsibility for the accuracy, completeness, or usefulness of any information, apparatus, product, or process disclosed, or represents that its use would not infringe privately owned rights. Reference herein to any specific commercial products, process, or service by trade name, trademark, manufacturer, or otherwise, does not necessarily constitute or imply its endorsement, recommendation, or favoring by the United States Government or the University of California. The views and opinions of authors expressed herein do not necessarily state or reflect those of the United States Govermment or the University of California, and shall not be used for advertising or product endorsement purposes.

This report has been reproduced directly from the best available copy.

Available to DOE and DOE contractors from the

Office of Scientific and Technical Information

P.O. Box 62, Oak Ridge, TN 37831

Prices available from (615) 576-8401, FTS 626-8401

Available to the public from the

National Technical Information Service

U.S. Department of Commerce

5285 Port Royal Rd.,

Springfield, VA 22161

This work was performed under the auspices of the U.S. Department of Energy, National Nuclear Security Administration by University of California Lawrence Livermore National Laboratory under Contract W-7405Eng-48. 


\section{Table of Contents}

OVERVIEW AND SUMMARY .......................................................................... 1

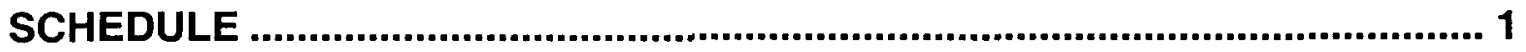

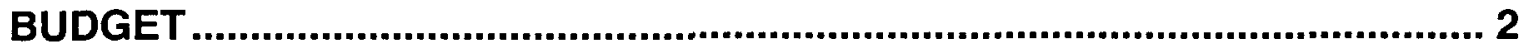

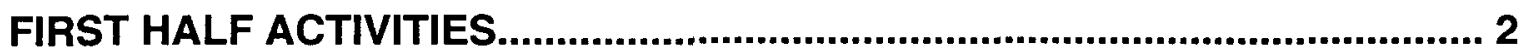

Drilled and Sealed Beryllium Capsules ......................................................................................................................2

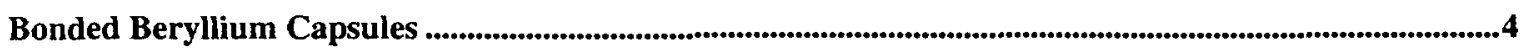




\section{NIF Cryogenic Target Systems Semi-Annual Report - First Half, 2003}

\section{Overview and Summary}

The initial NIF Cryogenic Target Systems (NCTS) major milestone for FY03 was to complete the conceptual design and a Conceptual Design Report (CDR). Due to actual FY03 NCTS funds available, this milestone has been postponed to FY2004. Some effort toward the CDR and related development activities did continue in the area of methods for fuel-filling of both beryllium and polymer ignition capsules. This work was performed mainly at General Atomics in collaboration with LANL and LLNL

\section{Schedule}

With the FY03 NCTS budget guidance, the schedule for the full indirect-drive ignition cryogenic systems for the NIF, shown in Figure 1, indicates completion in mid-FY10, with a first-article system available in early FY09 at the completion of integrated testing. The Statement of Mission Need will be complete in FY03, and the Conceptual Design Report in FY04

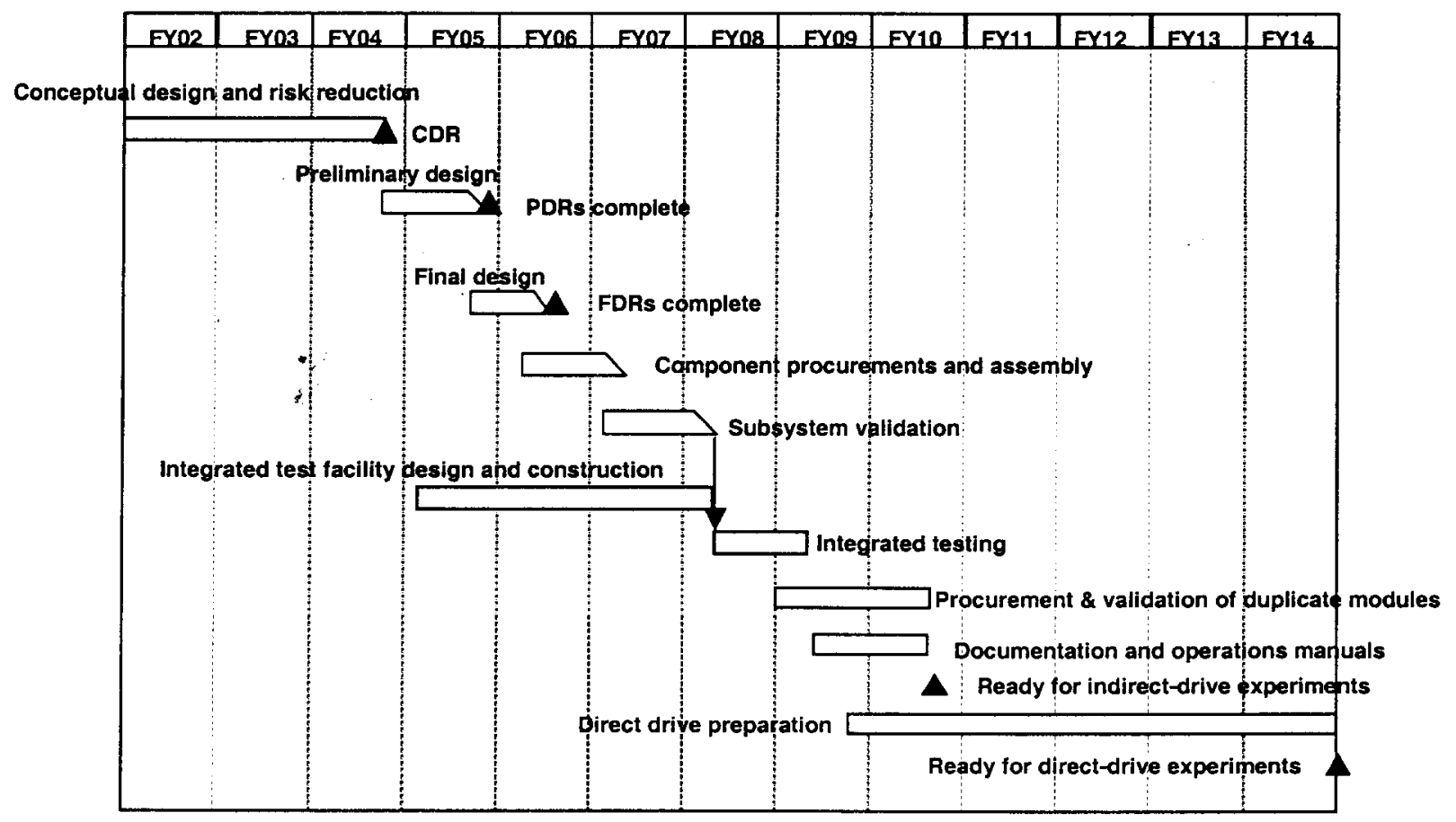

Figure 1. High-level schedule for the NCTS assuming FY03 budget guidance. 


\section{Budget}

The NCTS activities conducted during the first half of FY03 included work by General Atomics/Schafer, LANL, and LLNL. Progress has been hampered by the on-going appropriations process, due to the significant uncertainty surrounding the final FY03 funding available for the total NIF Director activities. The actual expenditures for the first two quarters of FY03 are $\$ 17 \mathrm{~K}$ at LLNL, and $\$ 239 \mathrm{~K}$ at General Atomics/Schafer. The report covering the second half of the year will include the total for the fiscal year.

\section{First Half Activities}

NCTS work breakdown structure element N.CR.4 "Beryllium Fill Systems," (Appendix C of the draft NCTS Program Execution Plan) is concerned with methods to fill indirect drive ignition targets with beryllium fuel capsules. Work that began in FY2002 to develop and examine concepts for beryllium capsule filling has continued into FY2003. This work was performed by General Atomics with input from Los Alamos National Laboratory (LANL) and LLNL.

Two principal approaches are being pursued to fill spherical beryllium-alloy capsules. In the first approach, a small hole is laser-drilled through the capsule wall, the capsule is filled with D$T$ through the hole, and the hole is laser-sealed, trapping the DT. In the second approach, a stack of mated pairs of Beryllium cylinders, each with a hemispherical cavity, is filled with highpressure D-T gas in a pressure vessel. The cylinder pairs are pressed together and heated to a high temperature. This diffusion-bonds each cylinder pair together, forming a spherical cavity filled with high-pressure D-T gas. After removal from the vessel, the outer surface of the bonded cylinder pair is machined into the desired spherical shape.

\section{Drilled and Sealed Beryllium Capsules}

GA proposed an improved method for filling a capsule by cryo-condensation of DT gas at low pressure in a small filling chamber, then laser sealing the fill hole at the top of the capsule through a window in the chamber. The scheme is depicted in Figure 2. 


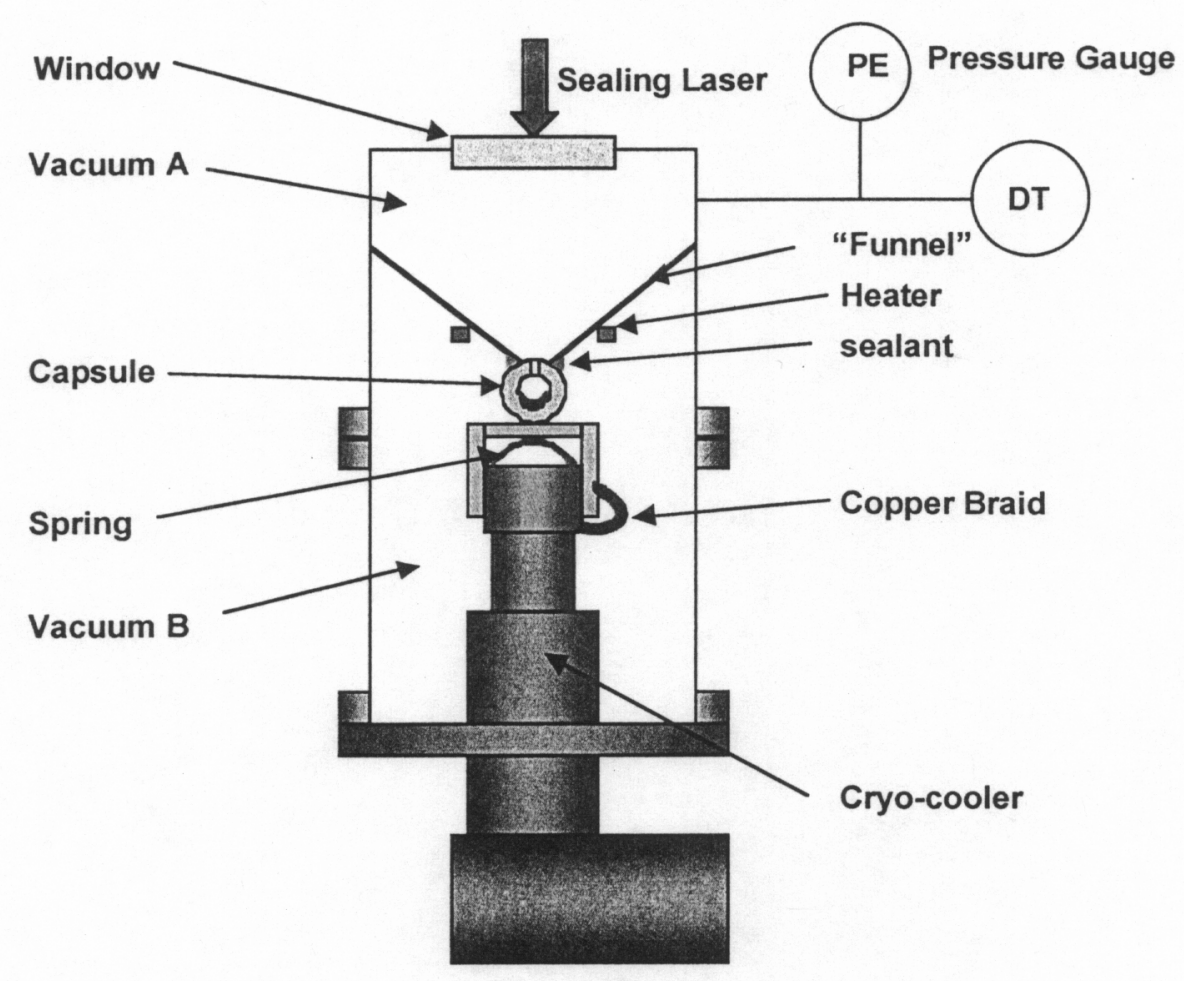

Figure 2. Low-pressure cryo-condensation method for filling beryllium capsules.

A "funnel" and the capsule, sealed with vacuum grease, separates the chamber into two spaces (A \& B). This minimizes the volume of D-T and prevents D-T from condensing on the cryocooler. A commercial cryo-cooler and a small local heater impose a thermal gradient between the top and the bottom of the capsule to condense the gas at the bottom of the capsule and keep the fill hole clear of condensate. Using a fill pressure between 200 and 300 torr allows rapid filling. The amount of D-T condensing in the capsule is determined from pressure measurements of the "Vacuum A" space. The D-T fill can be determined with $1 \%$ accuracy by limiting the volume of D-T gas with unknown density at the tip of the "funnel" to $\sim 5.2 \mathrm{~mm}^{3}$, maintaining the ambient temperature stable to $\pm 1 \mathrm{~K}$ and using a commercially available, high-accuracy pressure gauge.

A steady-state thermal analysis showed that the desired temperature distribution can be achieved in the beryllium capsule. The cryo-cooler keeps the bottom of the capsule at $16 \mathrm{~K}$. By applying a small heating power $(\sim 76 \mathrm{~mW})$ on the area surrounding the fill hole at the top of the capsule, the temperature of the hole can be maintained above $\sim 34 \mathrm{~K}$, keeping it clear of liquid D-T. The bottom half of the capsule stays below $\sim 23 \mathrm{~K}$, ensuring condensation.

GA proposed to use a commercially available, continuous-wave (CW) or short-pulse YAG laser to seal the fill hole of the beryllium capsule after filling. A transient thermal analysis showed that a 0.2 -ms pulse at 5.7 Watts seals the hole without significantly heating and vaporizing the DT condensed at the bottom of the capsule. The resulting plug of fused beryllium is long enough to resist an internal DT pressure of $400 \mathrm{~atm}$ at room temperature. This is illustrated in Figure 3. 
Initial YAG laser experiments by LLNL on $125-\mu \mathrm{m}$-thick beryllium foil have achieved localized melting, in accordance with GA's analytical predictions.
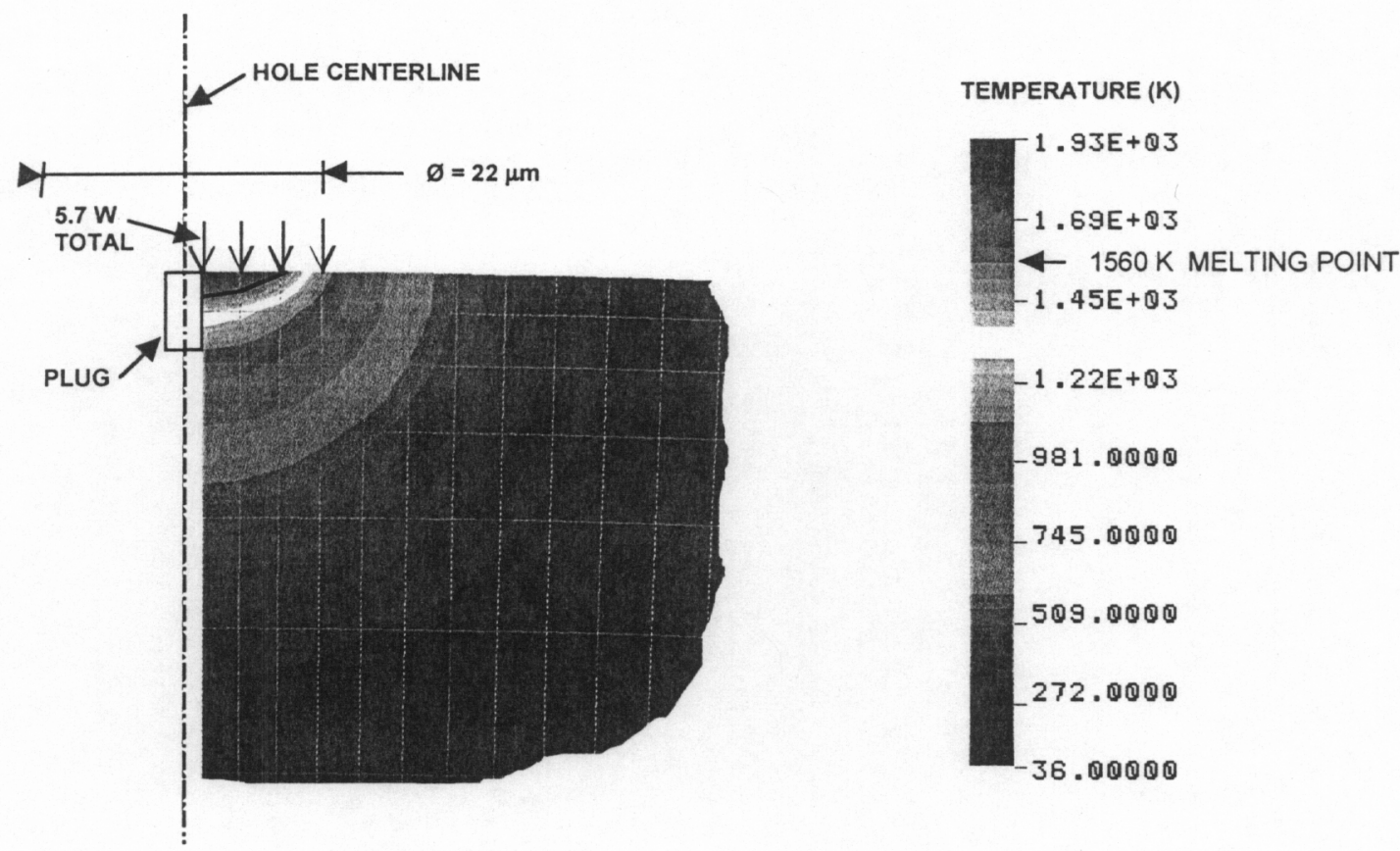

Temperature distribution near the hole opening at $0.2 \mathrm{~ms}$.

Figure 3. Results of thermal modeling of a sealing laser pulse.

\section{Bonded Beryllium Capsules}

GA performed a preliminary design of the filling and bonding cell, shown in Figure 4 below. It is based on a commercially available pressure vessel. The vessel cavity is lined with solid quartz insulation. An electrical heater, composed of a heating coil, a quartz tube, and radiation shields, is inserted into the insulated space. The beryllium cylinder pairs to be filled and bonded, kept slightly apart by curved disc springs, are stacked in an open cylindrical holder that is placed inside the heater, and the top quartz insulation is added (see Figure 5). The vessel closure, with a dead weight hung from an extension of the valve stem at the top, is put in place and sealed. The vessel is evacuated and back-filled with pressurized DT gas. The heater supplies $340 \mathrm{~W}$ to quickly heat the beryllium cylinder to the bonding temperature. Heat power is then reduced to $190 \mathrm{~W}$ to maintain this temperature. When the temperature and DT pressure have stabilized, the dead weight is lowered and brought to rest on top of the cylinder stack to apply the bonding pressure. After the required bonding time, the process is reversed, and the DT-filled and bonded cylinders can be removed for inspection and machining into spherical capsules. 


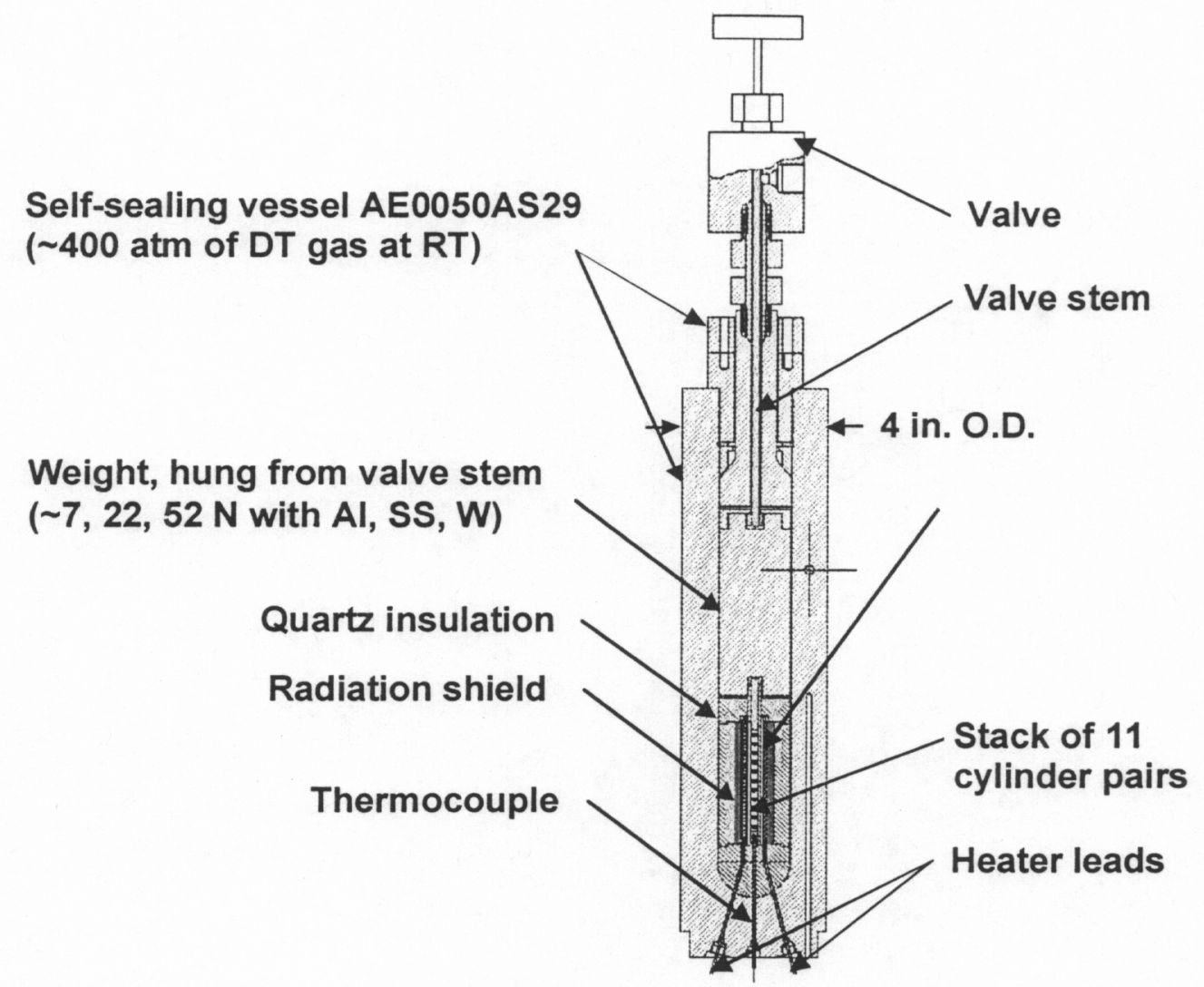

(Water-cooled copper cooling jacket and glove box not shown)

Figure 4. A high-pressure beryllium bonding apparatus.

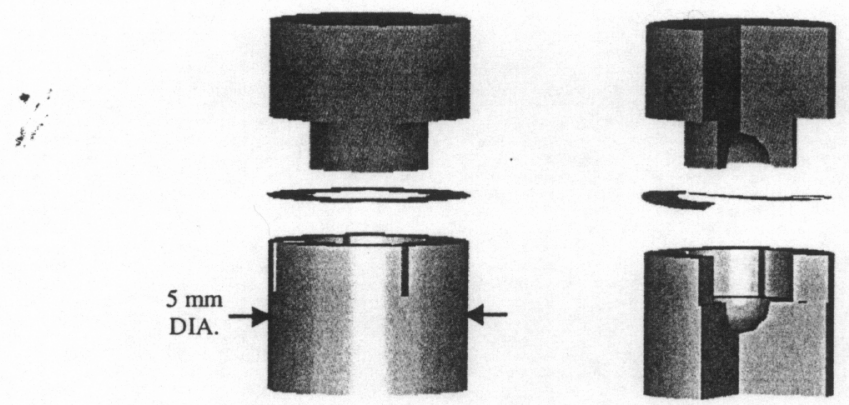

Figure 5. Two views of a typical cylindrical pair (with slots and spring to allow evacuation and filling before bonding).

A time-dependent thermal analysis shows that beryllium is heated to the bonding temperature in about three minutes and is kept at steady state with the lower-heat power. The exterior of the bonding apparatus remains at room temperature. 